
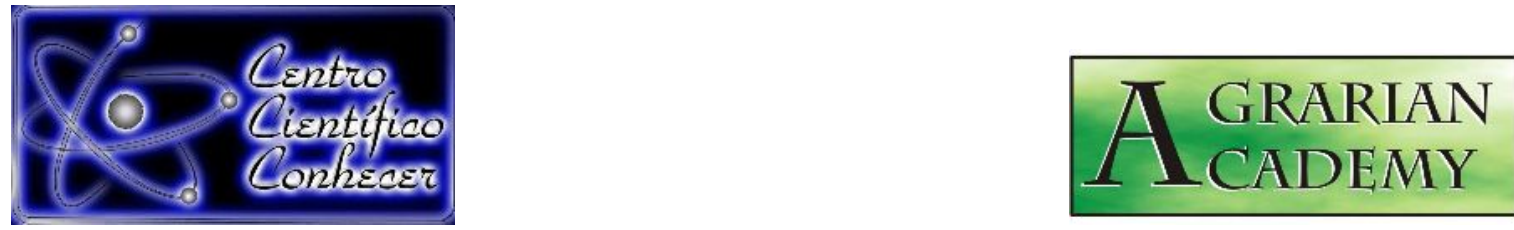

\title{
DENSIDADE E POROSIDADE DO SOLO EM PASTAGEM RECUPERADA E DEGRADADA, NA AMAZÔNIA OCIDENTAL
}

Marina Conceição do Carmo; J Jonas Machado Cunico ${ }^{1}$ Marta Raiara Gomes

Santos ${ }^{1}$; Poliana Kefler Monteiro da Silva1, Marcos Gomes de Siqueira ${ }^{1}$

${ }^{1}$ Graduando(a) do curso de Agronomia, Fundação Universidade Federal de

Rondônia - UNIR, Rolim de Moura, Brasil (agrobiologia2@hotmail.com).

Recebido em: 14/07/2018 - Aprovado em: 28/07/2018 - Publicado em: 31/07/2018

DOI: 10.18677/Agrarian_Academy_2018a15

\begin{abstract}
RESUMO
A porosidade do solo está diretamente ligada à textura e estrutura dos solos, inferindo na capacidade de drenagem e retenção do perfil, assim como na sua aeração. $O$ objetivo deste trabalho foi avaliar a densidade e porosidade dos solos em ambientes e profundidades diferentes. Foram selecionadas, na região de Rolim de Moura/RO, duas áreas. Uma constituída de solo com pastagem degradada outra de solo com pastagem recuperada. Em cada área foram abertas quatro trincheiras de $20 \mathrm{~cm}$ de profundidade, de cada trincheira foi coletado solo nas seguintes camadas $0-5 \mathrm{~cm}, 5-10 \mathrm{~cm}, 10-15 \mathrm{~cm}, 15-20 \mathrm{~cm}$. Os resultados mostram que a degradação da pastagem resulta no aumento da densidade do solo, assim como na redução da porosidade total e macroporosidade. A microporosidade não foi influenciada pelo estado da pastagem.
\end{abstract}

PALAVRAS CHAVE: física do solo, manejo do solo, Brachiaria brizantha.

\section{DENSITY AND POROSITY OF SOIL IN RECOVERED AND DEGRADED PASTURE IN THE WESTERN AMAZON}

\begin{abstract}
The porosity of the soil is directly linked to the texture and structure of the soils, inferring in the drainage and retention capacity of the profile, as well as its aeration. The objective of this work was to evaluate soil density and porosity in different environments and depths. Two areas were selected in the Rolim de Moura/RO region. One composed of soil with degraded pasture another of soil with recovered pasture. In each area four trenches were opened $20 \mathrm{~cm}$ deep, each trench was collected in the following layers $0-5 \mathrm{~cm}, 5-10 \mathrm{~cm}, 10-15 \mathrm{~cm}, 15-20 \mathrm{~cm}$. The results show that pasture degradation results in increased soil density as well as reduction of total porosity and macroporosity. Microporosity was not influenced by pasture status.

KEYWORDS: soil physics, soil management, Brachiaria brizantha.
\end{abstract}




\section{INTRODUÇÃO}

A pecuária é uma atividade que vem sendo desenvolvida no estado de Rondônia a décadas, com um perfil eminentemente de base familiar, a pecuária leiteira é praticada em mais de $1 / 3$ das propriedades rurais de Rondônia, sendo base da renda destas famílias (BRITO, 2011). Os sistemas de criação normalmente extensivos em regime de pastagens sujeitam os animais à escassez de forragem, comprometendo a produção. Este fator combinado com superlotações podem provocar alterações nos atributos físicos do solo (COSTA et al., 2000).

Moreira et al., (2005), verificaram em um latossolo vermelho distrófico que a degradação da pastagem aumenta a densidade do solo, a resistência e a penetração, bem como reduziu a porosidade. As características físicas do solo sofrem alterações de acordo com o tipo de manejo que este é submetido, e dentre os parâmetros físicos mais afetados por ação antrópica destaca-se a densidade do solo e a porosidade total (FERREIRA et al., 2010).

A porosidade remete diretamente na qualidade do solo, interferindo em atributos como a permeabilidade do solo, processos de infiltração, redistribuição da capacidade de retenção (RIBEIRO et al., 2007). Além de se relacionar com o crescimento radicular, compactação, meso e macro fauna. Esses atributos do solo podem ser modificados de acordo com o manejo adotado, por isso torna-se de extrema importância a utilização de práticas conservacionistas visando manter e melhorar essas características.

O objetivo deste trabalho foi avaliar a densidade do solo, porosidade total, macro e microporosidade em áreas de pastagens em situações visualmente degradada e recuperada.

\section{MATERIAIS E MÉTODOS}

A coleta do solo foi realizada em uma propriedade rural em Rolim de Moura/RO, linha 184 lado norte, $\mathrm{km}$ 12. A uma altitude média de $277 \mathrm{~m}$, localizada em latitude $11^{\circ} 34^{\prime} 58,52^{\prime \prime}$ S e longitude $61^{\circ} 46^{\prime} 14,45^{\prime \prime}$ W. O delineamento experimental adotado foi inteiramente casualizado em arranjo fatorial $2 \times 4$ com 4 repetições. O fator considerado foi o estado visual da pastagem degradada e recuperada e os tratamentos sendo as quatro profundidades.

Em ambas as áreas encontrava-se implantada a forrageira Brachiaria brizanta, e era feito pastejo regularmente. Em cada área foram abertas quatro trincheiras de $20 \mathrm{~cm}$ de profundidade, de cada trincheira foi coletado solo nas seguintes camadas $0-5 \mathrm{~cm}, 5-10 \mathrm{~cm}, 10-15 \mathrm{~cm}, 15-20 \mathrm{~cm}$, utilizando um anel volumétrico provido de um adaptador. No laboratório, após o preparo das amostras com estrutura preservada, essas foram saturadas por meio da elevação gradual de uma lâmina de água até atingir totalmente a altura do cilindro metálico.

Após a saturação das amostras, as mesmas foram pesadas e posteriormente foi realizado 0 procedimento para obtenção da macroporosidade pelo método da mesa de tensão, durante $24 \mathrm{~h}$, drenando as amostras num potencial equivalente a - 0,006 Mpa, conforme descrito pela Embrapa (1997). Considerou-se como microporosidade do solo o espaço poroso ocupado por água após a sucção exercida na mesa de tensão. A macroporosidade é obtida pela diferença entre a porosidade total e a microporosidade

A densidade do solo foi determinada utilizando amostras de solo com estrutura indeformada, coletadas em anéis volumétricos de diâmetro médio de 
$98,125 \mathrm{~cm}^{3}$ (EMBRAPA, 1997). A porosidade total ou volume total de poros foi calculada mediante a seguinte equação:

Porosidade total (\% vol.) $=100(1-\mathrm{Ds} / \mathrm{Dp})$

Em que: Dp é a densidade de partículas do solo e Ds é a densidade do solo, ambas expressas em $\mathrm{mg} \mathrm{m} \mathrm{m}^{-3}$. Os dados obtidos no experimento foram analisados por meio da análise de variância, foi aplicado o teste Tukey a $5 \%$ para comparação de médias. Para isso, foi utilizado o software ASSISTAT (SILVA ; AZEVEDO, 2016).

\section{RESULTADOS E DISCUSSÃO}

A densidade do solo foi maior na área degradada, decrescendo de acordo com a profundidade da camada (Tabela 1). Isso se explica devido a vulnerabilidade física da pastagem, deixando o solo mais suscetível a compactação e mais exposto aos processos erosivos. Em áreas de pastagens a compactação do solo é causada principalmente pela carga animal, o aumento da densidade é induzido pela força aplicada em superfície (KUNZ et al., 2013). Bono et al., (2013) avaliando as propriedades físicas do solo em pastagem de $B$. brizanta encontrou resultados semelhantes quanto a compactação do solo, onde a maior densidade foi encontrada nas camadas mais superficiais.

TABELA 1. Densidade nas diferentes profundidades em pastagem degradada e recuperada.

\begin{tabular}{lcccc}
\hline Tratamentos & \multicolumn{4}{c}{ Profundidade $(\mathrm{cm})$} \\
& $0-5$ & $5-10$ & $10-15$ & $15-20$ \\
\hline \multirow{2}{*}{ Degradado } & $1,3844 \mathrm{a}$ & $1,4308 \mathrm{a}$ & $1,0591 \mathrm{a}$ & $0,9928 \mathrm{a}$ \\
Recuperado & $1,0065 \mathrm{~b}$ & $0,9283 \mathrm{~b}$ & $0,9353 \mathrm{a}$ & $1,0998 \mathrm{a}$ \\
\hline CV\% & \multicolumn{4}{c}{8,14}
\end{tabular}

Médias seguidas pelas mesmas letras na coluna não diferem estatisticamente entre si pelo teste de Tukey ao nível de $5 \%$ de probabilidade.

Segundo Lima et al., (2013) a elevada densidade do solo, resulta em maior resistência a penetração, 0 que consequentemente restringe 0 rendimento e produção das culturas. Silva et al., (2014) observaram que conforme aumenta a compactação do solo reduz a macroporosidade, a aeração do solo, a altura das plantas e a matéria seca das raízes. Entretanto os valores encontrados neste estudo estão abaixo dos valores críticos para desenvolvimento das culturas, segundo Reinert e Reichert (2006) os valores de densidade que podem oferecer riscos ao desenvolvimento radicular situam-se em torno de $1,65 \mathrm{~g} \mathrm{~cm}^{3}$ para solos arenosos e $1,45 \mathrm{~g} \mathrm{~cm}^{3}$ para solos argilosos.

A porosidade total no solo recuperado foi significativamente maior nas três primeiras profundidades (Tabela 2) esse fator no solo degradado se reduziu conforme aumentou a densidade. Esse atributo no solo degradado é menor devido ao processo de compactação, o que aumenta a densidade, diminui a capacidade de infiltração e aumenta a exposição aos processos erosivos. A pastagem de braquiária na área recuperada teve efeito na estrutura do solo promovendo um aumento na quantidade de poros (MOREIRA et al., 2005). 
TABELA 2. Porosidade total nas diferentes profundidades em pastagem degradada e recuperada.

\begin{tabular}{lllcc}
\hline Tratamentos & \multirow{4}{l}{ Profundidade $(\mathrm{cm})$} \\
& $0-5$ & $5-10$ & $10-15$ & $15-20$ \\
\hline \multirow{2}{*}{ Degradado } & $0,44 \mathrm{~b}$ & $0,43 \mathrm{~b}$ & $0,38 \mathrm{~b}$ & $0,57 \mathrm{a}$ \\
Recuperado & $0,62 \mathrm{a}$ & $0,60 \mathrm{a}$ & $0,64 \mathrm{a}$ & $0,58 \mathrm{a}$ \\
\hline CV\% & \multicolumn{4}{c}{5,12}
\end{tabular}

Médias seguidas pelas mesmas letras na coluna não diferem estatisticamente entre si pelo teste de Tukey ao nível de $5 \%$ de probabilidade.

Esses resultados corroboram com os encontrados por Lima et al., (2013) em que a densidade do solo e a porosidade total foram inversamente proporcionais, e juntamente com a redução da porosidade o solo torna-se mais compacto e aumenta a resistência mecânica dificultando o desenvolvimento das plantas.

Segundo Oliveira et al., (2015) a porosidade total é importante indicador de qualidade do solo, uma vez que maior porosidade reflete em condições que o solo não se alterou com a pressão exercida pelo tráfego e pelo revolvimento. O uso inadequado do solo revolvendo-o excessivamente e a ausência de práticas conservacionistas, podem provocar o aumento da densidade, e reduzir a porosidade total e macroporosidade (SOARES et al., 2016). Os resultados para macroporosidade apresentaram-se melhores na área recuperada, porém foram inerentes a densidade do solo, em ambas as áreas independente da camada (Tabela 3).

TABELA 3. Macroporosidade nas diferentes profundidades em pastagem degradada e recuperada.

\begin{tabular}{lcccc}
\hline Tratamentos & \multicolumn{5}{c}{ Profundidade $(\mathrm{cm})$} \\
& $0-5$ & \multicolumn{4}{c}{$5-10$} & $10-15$ & $15-20$ \\
\hline \multirow{2}{*}{ Degradado } & $0,10 \mathrm{~b}$ & $0,11 \mathrm{~b}$ & $0,13 \mathrm{~b}$ & $0,11 \mathrm{~b}$ \\
Recuperado & $0,22 \mathrm{a}$ & $0,18 \mathrm{a}$ & $0,18 \mathrm{a}$ & $0,16 \mathrm{a}$ \\
\hline CV\% & \multicolumn{5}{c}{7,23}
\end{tabular}

Médias seguidas pelas mesmas letras na coluna não diferem estatisticamente entre si pelo teste de Tukey ao nível de $5 \%$ de probabilidade.

Segundo Neves Júnior et al., (2013) a macroporosidade é influenciada pelo sistema de manejo, e o aumento da densidade provoca a redução. Caetano et al., (2013) infere que pastagens com elevada degradação, sem correção ou fertilização, mantidas em pastejo contínuo tendem a reduzir o número de macroporos.

Resultados opostos a este trabalho foram observados por Bortolini et al., (2015) estudando as propriedades físicas do solo em sistema de integração lavoura pecuária, constatando que o pisoteio animal não interferiu de forma negativa na macroporosidade do solo. Para microporosidade não houve diferença significativa entre as áreas estudadas (Tabela 4) em qualquer camada os resultados mostraramse semelhantes. 
TABELA 4. Microporosidade nas diferentes profundidades em pastagem degradada e recuperada.

\begin{tabular}{|c|c|c|c|c|}
\hline \multirow{2}{*}{ Tratamentos } & \multicolumn{4}{|c|}{ Profundidade $(\mathrm{cm})$} \\
\hline & $0-5$ & & & $15-20$ \\
\hline & \multicolumn{4}{|c|}{ Microporosidade $\left(\mathrm{m}^{3} \mathrm{~m}^{-3}\right)$} \\
\hline Degradado & $0,65 a$ & $0,60 a$ & $0,55 a$ & $0,46 a$ \\
\hline Recuperado & $0,67 a$ & $0,61 a$ & $0,059 a$ & $0,49 a$ \\
\hline CV\% & & 7,5 & & \\
\hline \multicolumn{5}{|c|}{$\begin{array}{l}\text { Médias seguidas pelas mesmas letras na coluna não diferem estatisticamente } \\
\text { entre si pelo teste de Tukey ao nível de } 5 \% \text { de probabilidade. }\end{array}$} \\
\hline \multicolumn{5}{|c|}{$\begin{array}{l}\text { Esses resultados se confirmam com os encontrados por Silva et al., } \\
\text { (2014) em que avaliando os atributos físicos em área de neem, área com capim } \\
\text { elefante e área com braquiária, observaram que a microporosidade foi pouco } \\
\text { influenciada pela cobertura vegetal e manejo aplicado. Segundo Mazurana et } \\
\text { al., (2013) a microporosidade sofre pouca influência da cobertura vegetal e } \\
\text { tráfego sobre o solo, mas sim por características intrínsecas do solo, como a } \\
\text { textura e o teor de matéria orgânica. A quantidade de microporos é um atributo } \\
\text { de extrema importância presente nos solos, pois esses são responsáveis pela } \\
\text { retenção e armazenamento de água. } \\
\text { Os indicadores físicos de qualidade do solo estão relacionados com a } \\
\text { estrutura das partículas sólidas e a porosidade, o que reflete em limitações ao } \\
\text { desenvolvimento radicular, a emergência das plântulas, o movimento da água e } \\
\text { no potencial produtivo. Dentre esses indicadores encontra-se a porosidade } \\
\text { total, macro e microporosidade, densidade e resistência à penetração } \\
\text { (EFFGEN et al., 2014). Segundo Pezarico et al., (2013) esses indicadores } \\
\text { apresentam potencial para a detecção de alterações ambientais que são } \\
\text { causadas devido ao manejo adotado. Esses atributos devem ser identificados, } \\
\text { para que possam ser corrigidos, já que são modificados de acordo o manejo do } \\
\text { solo, e assim promover um sistema mais sustentável. }\end{array}$} \\
\hline
\end{tabular}

\section{CONCLUSÃO}

A degradação das pastagens resulta no aumento da densidade do solo, assim como na redução da porosidade total e macroporosidade. A microporosidade não foi influenciada pelo estado da pastagem.

\section{REFERÊNCIAS}

BONO, M. A. J.; MACEDO, M. C. M.; TORMENA, A. C. Qualidade física do solo em um latossolo vermelho da região sudoeste dos cerrados sob diferentes sistemas de uso e manejo. Revista Brasileira de Ciência do Solo, v. 37, n.3, p. 743-753, 2013. Disponível em: http://dx.doi.org/10.1590/S0100-06832013000300021.

BORTOLINI, D.; ALBURQUERQUe, A. J.; RECH, C.; MAFRA, L. A.; RIBEIRO FILHO, N. M. H. PÉRTILE, P. Propriedades físicas do solo em sistema de integração lavoura-pecuária em Cambissolo Húmico. Revista de Ciências Agroveterinárias, v.15, n.1, p.60-67, 2016. Disponível em: DOI: 10.5965/223811711512016060. 
BRITO, L. G. Sistema de produção de leite para Rondônia. Embrapa/ Empresa Brasileira de Pesquisa Agropecuária. Versão eletrônica, n.34. Porto Velho, 2011.

CAETANO, O. J.; VERGINASSI, A.; ASSIS, R. C. P.; CARNEIRO, C. A. M.; PAULINO, B. H. Indicadores de qualidade de um latossolo vermelho sob diferentes sistemas de uso e manejo. Global Science Technology, v. 06, n. 01, p.26 - 39, 2013. Disponível em: HTTP://DX.DOI.ORG/10.14688/1984-3801.V06N01A03.

COSTA, O. V.; COSTA, L. M.; FONTES, L. E. F.; ARAUJO, Q. R.; KER, J. C.; NACIF, P. G. S. Cobertura do solo e degradação de pastagens em área de domínio de Chernossolos no sul da Bahia. Revista Brasileira Ciência do Solo, n.24, p.843856, 2000. Disponível em: http://dx.doi.org/10.1590/S0100-06832000000400016.

EFFGEN, M. A. T.; PASSOS, R. R; ANDRADE, V. F.; LIMA, S. de. S. J.; REIS, F. E. dos.; BORGES, N. E. Propriedades físicas do solo em função de manejos em lavouras de cafeeiro conilon. Revista Ceres, v. 59, n.3, p. 414-421, 2012. Disponível em: http://dx.doi.org/10.1590/S0034-737X2012000300018.

EMBRAPA. Empresa Brasileira de Pesquisa Agropecuária. Serviço Nacional de Levantamento e Conservação de solos (Rio de Janeiro, RJ). 1997. Manual de métodos de análise de solos. 2.ed. Rio de Janeiro. 212 p.

FERREIRA, R. M.; TAVARES FILHO, J.; FERREIA, V. M. Efeitos de sistemas de manejo de pastagens nas propriedades físicas do solo. Revista Brasileira de Ciências Agrárias, v. 31, n. 4, p. 913-932, 2010. Disponível em: http://dx.doi.org/10.1590/S0100-06832009000200001.

KUNZ, M.; GONÇALVES, A. M. D. A. de.; REICHERT, M. J.; GUIMARÃES, L. M. R.; REINERT, J. D.; RODRIGUES, F. M. Compactação do solo na integração sojapecuária de leite em latossolo argiloso com semeadura direta e escarificação. Revista Brasileira de Ciência do Solo, v. 37, n.6, p.1699-1708, 2013. Disponível em: http://dx.doi.org/10.1590/S0100-06832013000600026.

LIMA, A. M. I.; ARAÚJO, C. M. de.; BARBOSA, S. R. Avaliação das propriedades físicas do solo em sistemas silvipastoris, região centro norte, estado do Piauí. Agropecuária Cientifica no Semiárido, v.9, n.1, p.117-124, 2013. Disponível em: DOI: http://dx.doi.org/10.30969/acsa.v9i1.252.

MAZURANA, M.; FINK, R. J.; SILVEIRA, H. V. da.; LEVIEN, R.; ZULPO, L.; BREZOLIN, D. Propriedades físicas do solo e crescimento de raízes de milho em um Argissolos vermelho sob tráfego controlado de máquinas. Revista Brasileira de Ciência do Solo, v.36, n.5, p.1185-1195, 2013. Disponível em: http://dx.doi.org/10.1590/S0100-06832013000500008.

MOREIRA, J. A. A.; OliveIRA, I. P. DE; GUIMARÃES, C. M.; STONE, L. F. Atributos químicos e físicos de um latossolo vermelho distrófico sob pastagens recuperada e degradada. Pesquisa Agropecuária Tropical, v.35, n.3, p.155151, 2005. Disponível em:< https://www.revistas.ufg.br/pat/article/view/2217> Acesso em: 8 nov. 2012. 
NEVES JÚNIOR, F. A.; SILVA, P. A. da.; NORONHA, C. N.; CERRI, C. C. Sistemas de manejo do solo na recuperação de uma pastagem degradada em Rondônia. Revista Brasileira de Ciência do Solo, v.37, n.1, p.232-241, 2013. Disponível em: http://dx.doi.org/10.1590/S0100-06832013000100024.

OLIVEIRA, S. M. D.; LIMA, P. R. de.; VERBURG, J. E. E. Qualidade física do solo sob diferentes sistemas de manejo e aplicação de dejeto líquido suíno. Revista Brasileira de Engenharia Agrícola e Ambiental, v.19, n.3, p.280-285, 2015. Disponível em: http://dx.doi.org/10.1590/1807-1929/agriambi.v19n3p280-285.

PEZARICO, R. C.; VITORINO, T. C. A.; MERCANTE, M. F.; DANIEL, O. Indicadores de qualidade do solo em sistemas agroflorestais. Revista de Ciências Agrárias, v.56, n.1, p. 40-47, 2013. Disponível em: http://dx.doi.org/10.4322/rca.2013.004.

REINERT, D.J. \& REICHERT, J.M. Propriedades físicas do solo. Santa Maria, Universidade Federal Santa Maria, 2006. 18p. Disponível em: < https://www.agro.ufg.br/up/68/o/An_lise_da_zona_n_o_saturada_do_solo_texto.pdf $>$ Acesso em: 13 jun. 2018.

RIBEIRO, K.D.; MENEZES, S.M.; MESQUITA, M.G.B.F.; SAMPAIO, F.M.T. Propriedades físicas do solo, influenciadas pela distribuição de poros, de seis classes de solos da região de Lavras - MG. Ciência e Agrotecnologia, v.31, n.4, p.1167-1175, 2007. Disponível em: http://dx.doi.org/10.1590/S141370542007000400033.

SILVA, F. A. S.; AZEVEDO, C. A. V. The Assistat Software Version 7.7 and its use in the analysis of experimental data. African Journal of Agricultural Research, v. 11, p. 3733-3740, 2016. DOI: 10.5897/AJAR2016.11522.

SILVA, L. R.; MATIAS, R. S. S.; LOBATO, R. G. M.; NÓBREGA, A. C. J. Atributos físicos do solo em diferentes coberturas vegetais na Região Sul do Piauí. Revista Caatinga, v. 27, n. 3, p. 160 - 168, 2014. Disponíel em: < https://periodicos.ufersa.edu.br/index.php/caatinga/article/view/2890> Acesso em: 03 jul. 2018.

SILVA, R. F. da.; ALBURQUERQUE, A. J.; COSTA, A. da. Crescimento inicial da cultura da soja em latossolo bruno com diferentes graus descompactação. Revista Brasileira de Ciência do Solo, v.38, n.6, pp.1731-1739, 2014. Disponível em: http://dx.doi.org/10.1590/S0100-06832014000600008.

SOARES, R. D. M.; CAMPOS, C. C. M.; OLIVEIRA, A. I.; CUNHA, M. J.; SANTOS, C. A. L.; FONSECA, S. J.; SOUZA, M. Z. de. Atributos físicos do solo em áreas sob diferentes sistemas de uso na região de Manicoré, AM. Revista de Ciências Agrárias, v.59, n.1, p. 9-15, 2016. Disponível em: http://dx.doi.org/10.4322/rca.2020. 